\title{
In Vivo Imaging of Cerebral Dopamine D3 Receptors in Alcoholism
}

\author{
David Erritzoe*,', Andri Tziortzi ${ }^{2,3}$, David Bargiela', Alessandro Colasanti ${ }^{1,2}$, Graham E Searle', \\ Roger N Gunn ${ }^{2,4}$, John D Beaver ${ }^{2}$, Adam Waldman ${ }^{5}$, David J Nutt', Massimo Bani', Emilio Merlo-Pich ${ }^{6}$, \\ Eugenii A Rabiner ${ }^{2}$ and Anne Lingford-Hughes' \\ 'Centre for Neuropsychopharmacology, Division of Brain Sciences, Faculty of Medicine, Imperial College London, London, UK; \\ ${ }^{2}$ Clinical Imaging Centre, GlaxoSmithKline, London, UK; ${ }^{3}$ FMRIB Centre, Department of Clinical Neurology, University of Oxford, Oxford, \\ UK; ${ }^{4}$ Division of Brain Sciences, Department of Medicine, Imperial College London, London, UK; ${ }^{5}$ Department of Imaging, Charing Cross Hospital, \\ London, UK; ${ }^{6}$ CEDD for Neurosciences, GlaxoSmithKline, Verona, Italy
}

Animal studies support the role of the dopamine D3 receptor (DRD3) in alcohol reinforcement or liking. Sustained voluntary alcohol drinking in rats has been associated with an upregulation of striatal DRD3 gene expression and selective blockade of DRD3 reduces ethanol preference, consumption, and cue-induced reinstatement. In vivo measurement of DRD3 in the living human brain has not been possible until recently owing to a lack of suitable tools. In this study, DRD3 status was assessed for the first time in human alcohol addiction. Brain DRD3 availability was compared between 16 male abstinent alcohol-dependent patients and 13 healthy non-dependent age-matched males using the DRD3-preferring agonist positron emission tomography (PET) radioligand [ ' $\mathrm{C}] \mathrm{PHNO}$ with and without blockade with a selective DRD3 antagonist (GSK598809 $60 \mathrm{mg}$ p.o.). In striatal regions of interest, where the [ $\left.{ }^{1} \mathrm{C}\right] \mathrm{PHNO}$ PET signal represents primarily DRD2 binding, no differences were seen in [ [ $\left.{ }^{\prime} \mathrm{C}\right] \mathrm{PHNO}$ binding between the groups at baseline. However, baseline [ $\left.{ }^{\prime \prime} \mathrm{C}\right] \mathrm{PHNO}$ binding was higher in alcohol-dependent patients in hypothalamus $\left(V_{T}: 16.5 \pm 4\right.$ vs I3.7 $\left.\pm 2.9, p=0.040\right)$, a region in which the [ I $\left.C\right] P H N O$ signal almost entirely reflects DRD3 availability. The reductions in regional receptor binding $\left(V_{T}\right)$ following a single oral dose of GSK598809 (60 mg) were consistent with those observed in previous studies across all regions. There were no differences in regional changes in $V_{T}$ following DRD3 blockade between the two groups, indicating that the regional fractions of DRD3 are similar in the two groups, and the increased [ ' ' C]PHNO binding in the hypothalamus in alcohol-dependent patients is explained by elevated DRD3 in this group. Although we found no difference between alcohol-dependent patients and controls in striatal DRD3 levels, increased DRD3 binding in the hypothalamus of alcohol-dependent patients was observed. This may be relevant to the development of future therapeutic strategies to treat alcohol abuse. Neuropsychopharmacology (2014) 39, I703-1712; doi:10.1038/npp.20 I4.18; published online 19 February 2014

Keywords: PET; dopamine; D3; alcohol addiction; PHNO

\section{INTRODUCTION}

Alcohol abuse contributes to an estimated $3.8 \%$ of global deaths and $4.6 \%$ of global disability-adjusted life-years, and alcoholism is particularly associated with the greatest impact (Rehm et al, 2009). Treatment for alcoholism can be highly effective, and although psychosocial approaches dominate the treatment field, pharmacotherapy can have an important adjunctive role if appropriately integrated (Lingford-Hughes et al, 2012). A wealth of evidence links dysfunction of the dopamine system with alcohol liking, self-administration, and reinforcement in animal models and also in humans under laboratory settings. Despite this, drugs modulating dopaminergic neurotransmission have limited clinical

*Correspondence: Dr D Erritzoe, Centre for Neuropsychopharmacology, Division of Brain Sciences, Faculty of Medicine, Imperial College London, Burlington Danes Building, Hammersmith Campus, 160 Du Cane Road, London WI2 ONN, UK, Tel: +020 7594 7047, Fax: +020 7594 6548, E-mail: d.erritzoe@imperial.ac.uk

Received 22 July 2013; revised 13 November 2013; accepted II December 2013; accepted article preview online 28 January 2014 efficacy, which may be due to lack of selectivity of these medications for the dopamine D3 receptor (DRD3) (Lingford-Hughes et al, 2012; Volkow et al, 2012). The absolute density of DRD3 is high in the 'limbic' dopaminergic system, and the DRD3 is hypothesized to be particularly relevant for the treatment of addictive disorders (Heidbreder et al, 2005; Landwehrmeyer et al, 1993; Murray et al, 1994; Sokoloff et al, 1990; Suzuki et al, 1998).

Evidence from animal studies supports a role for the DRD3 in alcohol reinforcement or liking. Selective DRD3 antagonism has been shown to reduce ethanol preference and consumption in alcohol-preferring and non-preferring rats (Thanos et al, 2005) and to reduce the number of reinforcements and amount of alcohol consumed in mice (Andreoli et al, 2003). Furthermore, either antagonism or partial agonism of DRD3 has been shown to reduce the alcohol deprivation effect and cue-induced reinstatement (Heidbreder et al, 2007; Vengeliene et al, 2006). The DRD3 also has an important role in mediating the effects of stress leading to drug-seeking behavior (Heidbreder et al, 2005). It has also been reported that a year of voluntary alcohol drinking in alcohol preferring, 
in high alcohol drinking, and in Wistar rats was associated with an upregulation of DRD3 gene expression in the striatum (Vengeliene et al, 2006). Interestingly, in humans a single dose of a selective DRD3 antagonist was recently shown to partially alleviate cigarette craving in short-term abstinent smokers (Mugnaini et al, 2013).

Neuroimaging of the dopaminergic system with positron emission tomography (PET) and single-photon emission computed tomography (SPECT) has been instrumental in characterizing this system in addiction in man (Martinez et al, 2007). Over the past two decades, the antagonist PET and SPECT radioligands $\left[{ }^{11} \mathrm{C}\right]$ raclopride, $\left[{ }^{11} \mathrm{C}\right]$ fallypride, $\left[{ }^{123} \mathrm{I}\right]$ epidepride, and $\left[{ }^{123} \mathrm{I}\right] \mathrm{IBZM}$ have been used to image the D2 receptor family. These in vivo imaging studies have revealed decreased D2 receptor availability in alcoholdependent patients (ADP) when compared with controls and in stimulant abuse. However, quantification of the D2 receptor family has limitations, because as antagonists these ligands bind with equal affinity to both the high $\left(\mathrm{DRD} 2_{\mathrm{HIGH}}\right)$ and the low (DRD2 $\left.{ }_{\mathrm{LOW}}\right)$ affinity states of the DRD2. The DRD2 $2_{\mathrm{HIGH}}$ primarily mediate the effects of dopamine (George et al, 1985; Leff, 1995; Liu et al, 2000). In addition, the PET/SPECT signal from these radioligands consists of a mix of DRD2 and DRD3 binding (Halldin et al, 1995; Mukherjee et al, 1999; Narendran et al, 2006; Strange, 2001; Videbaek et al, 2000). Lastly, the receptor quantification has mostly been limited to the striatum owing to the low level of extra-striatal DRD2/3 receptors and low affinity of the radiotracers.

Recently, the development of the agonist radioligand $\left[{ }^{11} \mathrm{C}\right] \mathrm{PHNO}$ permits imaging of the DRD $2_{\mathrm{HIGH}}$ in both striatal and some extrastriatal regions (Ginovart et al, 2007b; Searle et al, 2013; Tziortzi et al, 2011). In addition, DRD3 levels can be assessed as $\left[{ }^{11} \mathrm{C}\right] \mathrm{PHNO}$ has approximately 20 fold selectivity for DRD3 over DRD2 (Graff-Guerrero et al, 2010; Narendran et al, 2006; Rabiner et al, 2009; Searle et al, 2010; Searle et al, 2013). In combination with a selective DRD3 antagonist (eg, GSK598809 or GSK618334), $\left[{ }^{11} \mathrm{C}\right]$ PHNO PET has determined the relative contributions of DRD2 and DRD3 to the $\left[{ }^{11} \mathrm{C}\right]$ PHNO PET signal in healthy volunteers (Rabiner et al, 2009; Searle et al, 2013; Tziortzi et al, 2011). In the substantia nigra-ventral tegmentum (SNVTA) and hypothalamus, around $90 \%$ of $\left[{ }^{11} \mathrm{C}\right] \mathrm{PHNO}$ signal reflected DRD3. In the ventral pallidum and globus pallidus, this fraction was 71 and $66 \%$,, respectively, whereas it was $39 \%$ in the ventral striatum, $14 \%$ in dorsal putamen, and $21 \%$ in dorsal caudate (Searle et al, 2013).

In four recent imaging studies, the agonist DRD2/3 radioligands $\left[{ }^{11} \mathrm{C}\right] \mathrm{PHNO}$ (Boileau et al, 2012; Matuskey et al, 2011; Payer et al, 2013) and [ $\left.{ }^{11} \mathrm{C}\right] \mathrm{NPA}$ (Narendran et al, 2011) were used to compare DRD2/3 receptor availability between individuals with stimulant dependence and matched healthy controls. No significant difference between the groups in striatal DRD2/3 availability was found in contrast to evidence from the previous antagonist studies. As both $\left[{ }^{11} \mathrm{C}\right] \mathrm{PHNO}$ and $\left[{ }^{11} \mathrm{C}\right] \mathrm{NPA}$ have higher affinity for DRD3 relative to DRD2 compared with the antagonist ligands (Narendran et al, 2006), the authors speculated that the lack of difference could be a consequence of decreased DRD2 $2_{\mathrm{HIGH}}$ combined with increased DRD3 binding in stimulant dependence compared with healthy controls (Boileau et al, 2012; Narendran et al, 2011).
We therefore acquired $\left[{ }^{11} \mathrm{C}\right]$ PHNO PET images before and after a dose of a DRD3 antagonist, GSK598809, to determine for the first time whether any differences between abstinent ADP and non-dependent healthy individuals in $\left[{ }^{11} \mathrm{C}\right] \mathrm{PHNO}$ signal are due to a difference in DRD2 ${ }_{\mathrm{HIGH}}$ or DRD3 availability. Based on the pre-clinical evidence that DRD3 antagonism reduced alcohol liking or reinforcement, we hypothesized that DRD3 availability would be higher and DRD2 ${ }_{\mathrm{HIGH}}$ lower in abstinent ADP compared with nondependent healthy individuals. Specifically, we expected to observe higher total $\left[{ }^{11} \mathrm{C}\right]$ PHNO binding in DRD3 signalrich regions such as $\mathrm{SN}-\mathrm{VTA}$, as reported in the three recent $\left[{ }^{11} \mathrm{C}\right]$ PHNO studies in stimulant users (Boileau et al, 2012; Matuskey et al, 2011; Payer et al, 2013), and hypothalamus and lower total $\left[{ }^{11} \mathrm{C}\right] \mathrm{PHNO}$ binding in caudate and putamen where signal mostly represents DRD2 binding. In regions where the $\left[{ }^{11} \mathrm{C}\right] \mathrm{PHNO}$ signal represents both DRD2 and DRD3, such as thalamus, globus pallidum, and ventral striatum, we expected to detect a more pronounced decrease in binding after DRD3 blockade in patients with alcohol dependence, reflecting a higher fraction of DRD3 in these individuals.

\section{METHODS}

\section{Participants}

Abstinent ADP were recruited from outpatient programs in Central and North West London NHS Foundation Trust and associated local addiction services. Healthy volunteers were recruited from newspaper advertisements. All ADP met DSMIV criteria for alcohol dependence and had been abstinent from alcohol after undergoing detoxification with benzodiazepines for a minimum of 4 weeks at the time of scanning. Control participants (CTR) had no history of alcohol abuse or dependence and drank a maximum of 25 units of alcohol per week ( $200 \mathrm{~g} /$ week). Additional inclusion criteria for all participants were: (1) male; (2) age 24-60 years; (3) no previous or current Axis I disorders although a history of major depression was allowed for ADP; (4) no current or past history of abuse of or dependence on drugs other than nicotine, with a negative urine toxicology (a history of use of but not dependence on cannabis was allowed but not within the past 4 weeks before scanning); and (5) no significant medical condition or current use of medications. Participants were instructed to refrain from consuming caffeine- or xanthine-containing products on the day of the scans and underwent urine and breathalyzer tests to rule out recent drug and alcohol use. Participants were not allowed to smoke for $1 \mathrm{~h}$ before each brain (MRI and PET) scan.

Semi-structured interviews were administered to obtain lifetime history of substance use, including approximate quantification of lifetime alcohol and substance use (interviews adapted from Skinner and Sheu, 1982 and Copenhagen Stimulant Screening Questionnaire). Degree of alcohol dependence was assessed with Severity of Alcohol Dependence Questionnaire (SADQ) (Stockwell et al, 1994), alcohol craving with Alcohol Urge Questionnaire (Bohn et al, 1995), and nicotine dependency with the Fagerstrom Test for Nicotine Dependence (Heatherton et al, 1991). Symptoms of depression and anxiety were characterized using Beck Depression Inventory (BDI; Beck, 1961), Spielberger Trait 
Anxiety Scale, and Spielberger State Anxiety Scale (SSAI; Spielberger et al, 1983). Premorbid IQ was assessed with the National Adult Reading Test (NART-R) (Blair and Spreen, 1989).

The study was sponsored by the Imperial College London, London, UK and approved by local ethics committee and all participants provided informed, written consent. Brain scans were carried out at GSK Clinical Imaging Centre (now Imanova), Hammersmith Hospital, London, UK.

\section{Imaging}

All participants underwent two $\left[{ }^{11} \mathrm{C}\right] \mathrm{PHNO}$ PET scans before and $3 \mathrm{~h}$ after administration of $60 \mathrm{mg}$ of GSK598809. For details regarding preparation of $\left[{ }^{11} \mathrm{C}\right] \mathrm{PHNO}$, see Plisson et al (2012) and for acquisition of PET images, collection of arterial blood samples, derivation of input function, and motion correction, see Searle et al (2013). Venous blood was sampled for measurements of GSK598809 concentration at the beginning of the second PET scan.

To aid the definition of the regions of interest (ROIs), high resolution structural MRIs and two components of the FLAWS sequence (Tanner et al, 2012) were acquired on 3-Tesla MR scanner (Magnetom Trio Syngo MR B13 Siemens 3T; Siemens AG, Medical Solutions) to provide a T1-weighted contrast and WM nulled image in a single scan. T1-weighted 3D MPRAGE volumes were acquired using the ADNI-GO recommended parameters: $256 \times 192 \mathrm{~mm}$ field of view, $1 \mathrm{~mm}^{3}$ isotropic resolution. The inversion times for the T1-weighted and the WM nulled images were 409 and 1100 ms, respectively.

\section{ROIs and Derivation of $\left[{ }^{11} \mathrm{C}\right]$ PHNO PET Outcome Measures}

Ten ROIs were analyzed: A $\left[{ }^{11} \mathrm{C}\right]$ PHNO-binding dopaminergic midbrain region (consisting of substantia nigraventral tegmentum (SN-VTA)), ventral pallidum (VP), globus pallidum internal (GPi), globus pallidum external (GPe), ventral striatum (VST), thalamus (THA), caudate (CD), putamen (PU), amygdala (AMY), and hypothalamus (HYP). The ROIs, except SN-VTA, were defined manually on each subject's MRI according to Tziortzi et al (2011) and amygdala according to Colasanti et al (2012). The delineation of the GPi and GPe was performed at first on the transverse slices using the white matter nulled image. The delineation started at the most dorsal slices where only the GPe is visible. Moving ventral, the thin white matter lamina, which separates the GPi and GPe, comes into view. The lamina is used to define the lateral and medial boundaries of the GPi and GPe, respectively. After the delineation of the two structures on the transverse plane, the operator switches to the coronal plane to refine the definition of the structures. This is particularly important for the delineation of the medial area of the GPi. SN-VTA was defined on each subject's baseline PET integral image, as the contrast between SN and surrounding tissue was insufficient for accurate delineation on the T1 MR images (Tziortzi et al, 2011). The gray matter (GM) of the dorsal cerebellum (CER), used as a reference region, was defined via nonlinear registration (using SPM5b; Wellcome Trust Centre for Neuroimaging, http://www.fil.ion.ucl.ac.uk/spm) of a template MRI (ICBM 52, http://www.bic.mni.mcgill.ca/
ServicesAtlases/ICBM152NLin2009) and corresponding brain atlas (Tziortzi et al, 2011). The cerebellar ROI did not include the vermis in order to minimize the presence of DRD3. Each ROI was then applied to the dynamic PET data to derive regional time-activity curves (TACs). The T1-weighted images were segmented into GM, white matter (WM), and cerebrospinal fluid (CSF) images that represent the probability of any given voxel containing GM, WM, or CSF. Each subject's GM image was used to mask the cortical regions and the cerebellum, and the masked ROIs were subsequently used to estimate the cortical GM volumes. For the manually defined subcortical ROIs, the entire ROI was used to estimate the GM volumes.

$\left[{ }^{11} \mathrm{C}\right]$ PHNO rate constants $\left(K_{1}-k_{4}\right)$ were estimated using a two tissue compartment (2TC) plasma input model as described previously (Searle et al, 2013). Subsequently, the total volume of distribution $\left(V_{\mathrm{T}}\right)$, defined as the equilibrium partition coefficient between tissue and plasma, was derived for each ROI;

$$
V_{\mathrm{T}}=\left(\mathrm{K}_{1} / \mathrm{k}_{2}\right)\left(1+\left(\mathrm{k}_{3} / \mathrm{k}_{4}\right)\right)
$$

Subsequently, $\mathrm{BP}_{\mathrm{P}}$ and $\mathrm{BP}_{\mathrm{ND}}$ in the target regions were calculated:

$$
\begin{aligned}
& \mathrm{BP}_{\mathrm{P}}=V_{\mathrm{T}}-V_{\mathrm{ND}} \\
& \mathrm{BP}_{\mathrm{ND}}=\left(V_{\mathrm{T}}-V_{\mathrm{ND}}\right) / V_{\mathrm{ND}}
\end{aligned}
$$

where $V_{N D}$ is the nondisplaceable volume of distribution and $\mathrm{BP}_{\mathrm{P}}$ and $\mathrm{BP}_{\mathrm{ND}}$ are the binding potentials derived as the ratio at equilibrium of specifically bound radioligand to that of total parent radioligand in plasma and to that of nondisplaceable radioligand in tissue, respectively.

In addition, the Simplified Reference Tissue Model (SRTM) (Gunn et al, 1997; Lammertsma and Hume, 1996), using cerebellum as the reference region, was applied to derive $\mathrm{BP}_{\mathrm{ND}}$. In order to distinguish the two $\mathrm{BP}_{\mathrm{ND}}$ outcome measures from SRTM and 2TC kinetic analysis, they will be referred to as $\mathrm{BP}_{\mathrm{ND}(\mathrm{SRTM})}$ and $\mathrm{BP}_{\mathrm{ND}(2 \mathrm{TC})}$, respectively.

For $V_{\mathrm{T}}, \mathrm{BP}_{\mathrm{P}}$, and $\mathrm{BP}_{\mathrm{ND}}$ values, a $\mathrm{DRD} 3 / \mathrm{DRD} 2$ binding ratio measure was created by dividing SN-VTA with caudate-putamen (average binding in these two regions) binding (Boileau et al, 2012). By re-scanning with $\left[{ }^{11} \mathrm{C}\right]$ PHNO after administration of a selective DRD3 antagonist, the degree of blockade of the $\left[{ }^{11} \mathrm{C}\right] \mathrm{PHNO}$ signal reflects a decrease in DRD3 binding. This blockade, referred to as ' $\triangle \mathrm{DRD} 3(\%)$ ', also served as outcome measure and for $V_{\mathrm{T}}$ and $\mathrm{BP}_{\mathrm{ND}}$ was calculated as follows:

$\Delta \mathrm{DRD} 3 V_{\mathrm{T}}(\%)=\left(V_{\mathrm{T}(\text { pre }- \text { block })}-V_{\mathrm{T}(\text { post }- \text { block })} / V_{\mathrm{T}(\text { pre }- \text { block })}\right) * 100$

$\Delta \mathrm{DRD} \mathrm{BP}_{\mathrm{ND}}(\%)=\left(\mathrm{BP}_{\mathrm{ND}(\text { pre }- \text { block })}-\mathrm{BP}_{\mathrm{ND}(\text { post }- \text { block })} / \mathrm{BP}_{\mathrm{ND}(\text { pre }- \text { block })}\right) * 100$

\section{Plasma Measurements of GSK598809}

High-performance liquid chromatography tandem mass spectrometry (HPLC-MS/MS) was used to quantify plasma levels of GSK598809 sampled $3 \mathrm{~h}$ post administration (beginning of the second PET scan). Two hundred 
Table I Demographics, Personality, and Symptom Measures

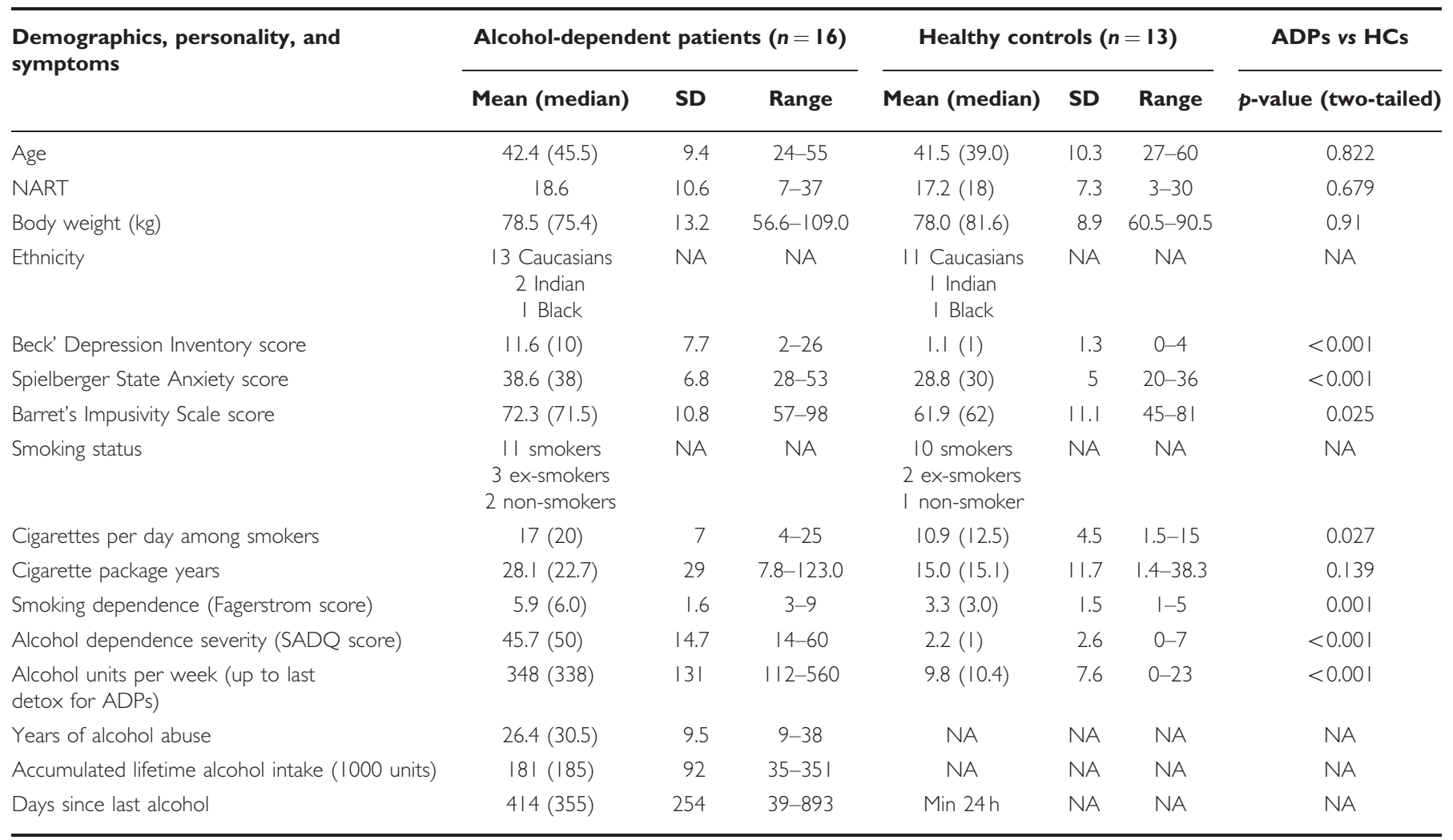

microliters acetonitrile, containing haloperidol-d4 as internal standard, was added to $50 \mu \mathrm{l}$ of standard. QC or sample was put in a 2-ml polypropylene tube and mixed for $1 \mathrm{~min}$. Following centrifugation at $12000 \mathrm{rpm}$ to compact the protein pellet, $100 \mu \mathrm{l}$ of the supernatant was then mixed with $100 \mu \mathrm{l} 0.1 \%$ formic acid and $25 \mu \mathrm{l}$ injected onto the HPLC/MS/MS. Column was a Grace Altima $150 \times 2.1 \mathrm{~mm}^{2}$ $5-\mu \mathrm{m} \mathrm{C} 18$ held at $60{ }^{\circ} \mathrm{C}$. Mobile phase was $55 \%$ acetonitrile/ $45 \% 0.1 \%$ formic acid, pumped at $400 \mu \mathrm{l} / \mathrm{min}$. Detection was by positive ion-spray and MRM masses: GSK598809 $482.0 \rightarrow$ 286.0, Haloperidol-d4 380.1 $\rightarrow$ 169.1.

\section{Statistics}

Group differences in PET outcome measures, in sociodemographic data, tobacco and alcohol use, and in scanning-related variables were tested using the Student's unpaired two-tailed $t$-test. To explore whether PET outcome measures and other variables, such as drinking parameters, smoking parameters, and psychometric data, were related, multiple linear regression analysis with $V_{\mathrm{T}}$ or $\Delta$ DRD3 $V_{\mathrm{T}}$ (\%) was included as the dependent variable. Age was also included as a covariate in these analyses as DRD2/3 levels decline with age (Antonini et al, 1993; Ichise et al, 1998; Ishibashi et al, 2009; Rinne et al, 1990; Severson et al, 1982; Volkow et al, 1998; Wong et al, 1997). To assess whether there was a significant $V_{\mathrm{T}}$ blockade in the cerebellum, onetailed paired $t$-test for pre- $v s$ post-blockade cerebellar $V_{\mathrm{T}}$ values for each group was applied. When comparing injected masses for the four conditions (pre- and postblockade for both the groups), one-way analysis of variance was conducted. In cases where assumptions of normally distributed data were violated, two-tailed nonparametric test (Mann-Whitney) and nonparametric signed rank test (Kruskal-Wallis) were used.

\section{RESULTS}

\section{Participants and Demographics}

Sixteen male ADP (42.4 \pm 9.4 years) and 13 male CTR (41.5 \pm 10.3 years) were included in the study. For one ADP an arterial line could not be inserted, and consequently only SRTM BP ${ }_{\mathrm{ND}}$, and not $V_{\mathrm{T}}$, could be estimated. Table 1 describes demographic and clinical variables of mood, alcohol, tobacco and drug use, and personality measures. No group differences were observed for the following: age $(p=0.82)$, body weight $(p=0.91)$, ethnicity, premorbid IQ (NART) score $(p=0.70)$, or composition of current/former/non-smokers. However, ADP smoked more cigarettes per day than CTR $(p=0.03)$ and had higher Fagerstrom Nicotine Dependence Scale scores $(p<0.01)$. ADP scored higher than CTR on all measures of alcohol consumption and dependence $(p<0.01)$ and had been abstinent for $415 \pm 254$ (range: 39-893) days before scanning. Although participants with current clinical depression or anxiety were excluded, ADP reported higher scores on depressive mood and anxiety (all: $p<0.01$; Table 1).

\section{PET Results}

Regional pre- and post-blockade $\left[{ }^{11} \mathrm{C}\right] \mathrm{PHNO} V_{\mathrm{T}}, \mathrm{BP}$, and $\mathrm{BP}_{\mathrm{ND}}$ values are presented in Table 2. Administration of 
GSK598809 resulted in a significant decrease in cerebellar $V_{\mathrm{T}}(8.3 \pm 7.4$ and $11.4 \pm 9.7 \%, p=0.002$ and $p<0.001$ for CTR and ADP, respectively). The presence of a specific binding component in the $\left[{ }^{11} \mathrm{C}\right]$ PHNO signal in the cerebellum led us to use the $V_{\mathrm{T}}$ as the primary outcome measure.

Group comparison of the total $\left[{ }^{11} C\right] P H N O$ binding. Total (or baseline) [ $\left.{ }^{11} \mathrm{C}\right]$ PHNO $V_{\mathrm{T}}$ was significantly higher in ADP compared with CTR in the hypothalamus (17.2\% difference, $p=0.04$, uncorrected) but not in any other region: striatum (caudate, putamen, and ventral striatum; $4.8 \%, p=0.40 ; 1.9 \%, p=0.82$; and $1.5 \%, 0.88$; respectively), amygdala $(6.1 \%, p=0.12)$, external pallidum $(-5.7 \%$, $p=0.54)$, cerebellum $(6.0 \%, p=0.16)$, and SN-VTA region $(5.1 \%, p=0.67)$. In the thalamus, ventral pallidum, and internal pallidum, there were trends towards higher binding in ADP compared with CTR $(9.4 \%, p=0.08 ; 16.2 \%, p=0.08$; and $22.7 \%, p=0.09$; respectively). The calculated VTA-SN/ $\mathrm{CD}$-PU binding ratios did not differ between the ADP and CTR groups, see Table 2. Correction for age did not change any of these regional findings significantly (data not shown).

Plasma levels of GSK598809. Plasma levels of GSK598809 at the beginning of the post-GSK598809 PET scan $(3 \mathrm{~h}$ after dosing) did not differ between the two groups (ADP: $359 \pm 113 \mathrm{ng} / \mathrm{ml}$ vs CTR: $401 \pm 144 \mathrm{ng} / \mathrm{ml}, p=0.409$ ).

Effect of GSK598809 on $\left[{ }^{11}\right.$ C]PHNO binding. Reductions of $\left[{ }^{11} \mathrm{C}\right]$ PHNO $V_{\mathrm{T}}$ after GSK598809 blockade were most pronounced in the SN-VTA, hypothalamus, and ventral pallidum (approximately $40 \%$ ), whereas $V_{\mathrm{T}}$ changed to a lesser extent in the caudate, putamen, and cerebellum (10$14 \%$ ), see Table 2 (lower section). There was no significant difference between groups in the degree of post-block $V_{\mathrm{T}}$ decrease in any region. Adjusting the change in $V_{\mathrm{T}}$ for plasma levels of GSK598809 measured at the start of the post-GSK598809 PET scan did not change this result.

\section{Injected Mass of PHNO and Plasma-Free Fraction}

There was no difference in average PHNO mass injected across the four conditions (CTR baseline: $1.5 \pm 0.3 \mu \mathrm{g}$, CTR post GSK598809: $1.4 \pm 0.3 \mu \mathrm{g}$, ADP baseline: $1.4 \pm 0.3 \mu \mathrm{g}$, ADP post GSK598809 : $1.3 \pm 0.3 \mu \mathrm{g}$, ANOVA: F[3,57], $p=0.577)$. Also, no differences were found after correcting for injected mass per $\mathrm{kg}$ body weight (ANOVA: F[3,57], $p=0.340$ ). There were no significant relationships between injected mass per $\mathrm{kg}$ body weight and regional $V_{\mathrm{T}}$ values ( $p$-values between 0.286 and 0.938 , data not shown). The plasma-free fraction, $f_{p}$, did not differ between the groups (CTR: $0.33 \pm 0.05, \mathrm{ADP}: 0.34 \pm 0.05, p=0.589$ ).

\section{Effect of Age}

There was a significant negative association between age and baseline $V_{\mathrm{T}}$ in SN-VTA $(R=0.26, \quad \mathrm{~F}[1,26]=9.3$, $p=0.005)$ and in putamen $(R=0.18, \quad \mathrm{~F}[1,26]=5.6$, $p=0.025)$ when ADP and CTR were combined. In SNVTA, this effect was mainly driven by the CTR group (ADP: $R=0.26, \mathrm{~F}[1,13]=4.47, p=0.054$; CTR: $R=0.38$,
$\mathrm{F}[1,11]=6.8, p=0.025)$ and in putamen mainly by the ADP group (ADP: $R=0.38, \quad \mathrm{~F}[1,13]=8.0, \quad p=0.014 ; \quad$ CTR: $R=0.014, \mathrm{~F}[1,11]=0.16, p=0.697)$. In the hypothalamus, there was a trend to a negative association with age in the full sample $(R=0.13, \mathrm{~F}[1,26]=4.0], p=0.057)$, an effect driven by the ADP subgroup (ADP: $R=0.57, \mathrm{~F}[1,13]=17.1$, $p=0.001$; CTR: $R=0.008, F[1,11]=0.1], p=0.773)$. No significant relationships between $V_{\mathrm{T}}$ and age were detected in other regions.

In the ADP group $(R=0.33, \mathrm{~F}[1,12]=6.0, p<0.031)$ but not in the full sample or in the CTR group, the degree of DRD3 blockade was negatively associated with age in both thalamus and putamen. No other significant relationships between degree of DRD3 blockade and age were detected in any other regions.

\section{GM Volumes}

There was no significant overall effect of group (Wilks' $\lambda 0.51$, $\mathrm{F}[1,29]=1.61, p=0.186$ ) or age (Wilks' $\lambda 0.62, \mathrm{~F}[1,29]=1.05$, $p=0.448$ ) when entering all regional GM volumes into a multivariate linear regression analysis. However, post-hoc analysis and after correcting for age revealed that only the cerebellum was significantly smaller $(8.5 \%, \mathrm{~F}[1,29]=4.64$, $p=0.041)$ in ADP compared with CTR. Correction for GM volumes did not change the group results (only data without correction for volume is presented in Table 2) from the group comparison of $V_{\mathrm{T}}$ values in any of the regions.

\section{Relationships between $V_{\mathrm{T}}$ Data and Clinical Measures}

Alcohol consumption. Neither SADQ score nor length of abstinence were significantly related to $V_{\mathrm{T}}$ or to the degree of DRD3 blockade in any of the regions among ADP. The lifetime alcohol intake was positively associated with $V_{\mathrm{T}}$ in the caudate but not in VST, putamen, or SN-VTA. In the thalamus, $V_{\mathrm{T}}$ as well as the degree of DRD3 blockade was positively associated with lifetime alcohol intake.

Smoking. The full sample was divided into three groups; current smokers $(n=20)$, former smokers $(n=5)$, and never-smokers $(n=3)$. There were no significant differences in $V_{\mathrm{T}}$ in any ROI between these groups. Similarly, there were no significant group difference in regional $V_{\mathrm{T}}$ when dividing the entire group of currently smoking ADP and CTR into two groups based on low and high scores on the Fagerstrom Test for Nicotine Dependence (low dependence: 0-4 vs medium-to-high dependence: 5-10). Additionally, in a regression analysis the score was not associated with $V_{\mathrm{T}}$ in any region (data not shown).

Barrett's Impulsiveness Scale (BIS). The ADP scored significantly higher than CTR (BIS: $72 \pm 11$ vs $62 \pm 11$, respectively, $p=0.025$ ). The BIS score was not significantly correlated with $V_{\mathrm{T}}$ or DRD3 blockade in any region.

Symptom scores. There were no significant relationships between depression (BDI) score and $V_{\mathrm{T}}$ in any region. In contrast, there was a significant positive correlation between SSAI score and $V_{\mathrm{T}}$ in the thalamus, amygdala, and hypothalamus in the full sample. The degree of DRD3 
Table 2 Regional I IC-PHNO Binding Data; Baseline (upper section) and after Blockade with the DRD3 Antagonist, GSK598809 (lower section)

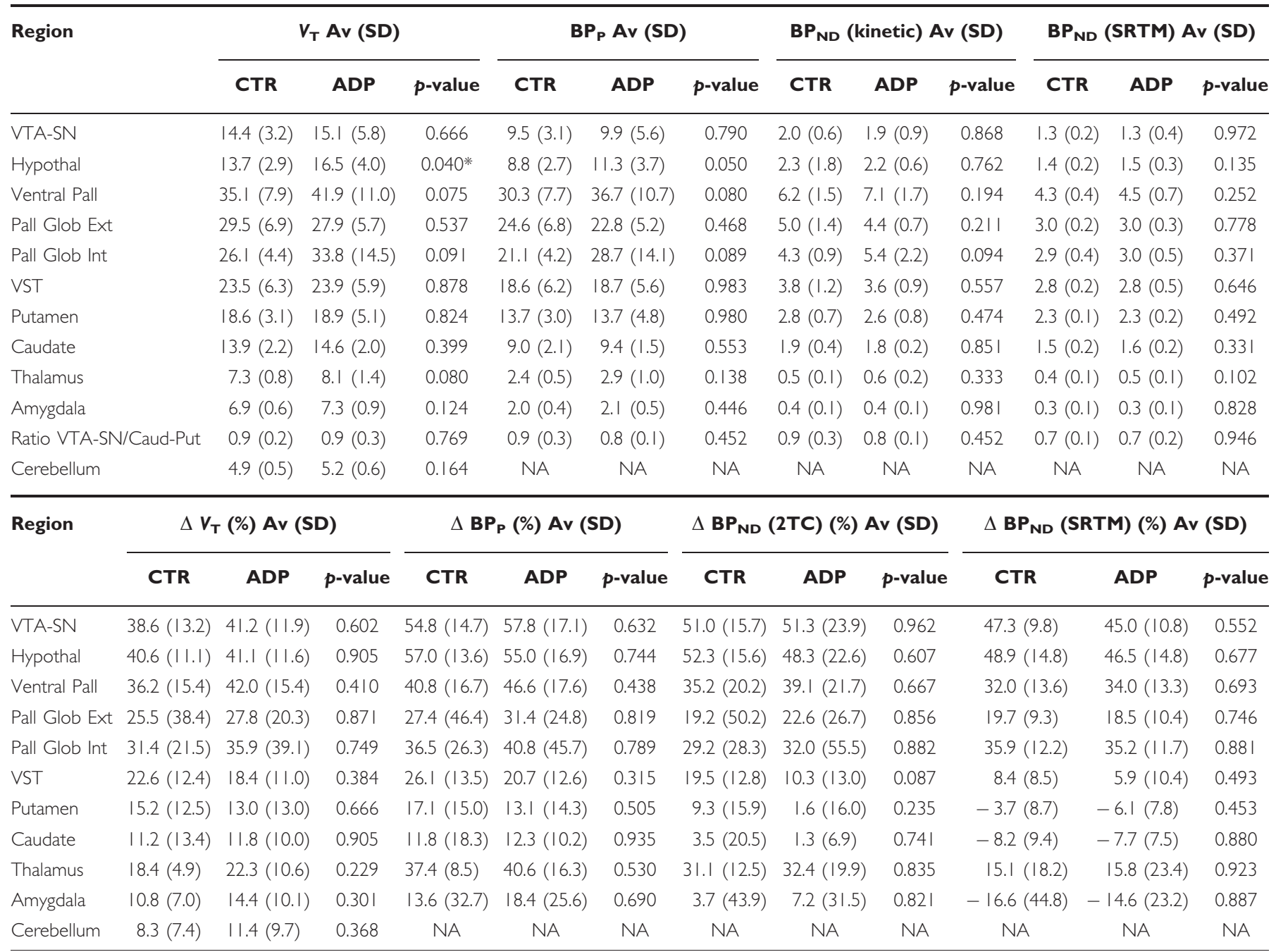

Table 2 Regional I IC-PHNO binding data; baseline (upper section) and after blockade with the DRD3 antagonist, GSK598809 (lower section). *P<0.05.

blockade was also positively related to SSAI score in the thalamus $(p=0.050)$ and trend-wise positively related in the amygdala $(p=0.058)$.

\section{DISCUSSION}

We report here the first in vivo brain imaging study investigating DRD3 receptor levels in addiction using the DRD3-preferring agonist $\left[{ }^{11} \mathrm{C}\right] \mathrm{PHNO}$ as PET radioligand with a selective DRD3 blocker. We did not confirm our hypothesis of global increase in DRD3 receptor availability in abstinent ADP when compared with controls. In particular, we did not see any group differences in total $\left.{ }^{[11} \mathrm{C}\right]$ PHNO binding or in the degree of DRD3 blockade in striatal regions or in the SN-VTA region as we had hypothesized. Interestingly, we did find evidence of higher DRD3 binding in hypothalamus among abstinent ADP. A lack of difference in total $\left[{ }^{11} \mathrm{C}\right] \mathrm{PHNO}$ binding in the dorsal part of the striatum (caudate and putamen) is suggestive of unaltered DRD2 $2_{\mathrm{HIGH}}$ binding in abstinent ADP.

Previous PET/SPECT studies in alcoholism conducted with the DRD2/3 antagonist radiotracers $\left[{ }^{11} \mathrm{C}\right]$ raclopride, $\left[{ }^{18} \mathrm{~F}\right]$ desmethoxyfallypride, $\left[{ }^{123} \mathrm{I}\right] \mathrm{IBZM}$, and $\left[{ }^{123} \mathrm{I}\right]$ epidepride have consistently reported lower (7-22\%) DRD2/3 availability in the striatum of patients compared with controls (Martinez et al, 2007). Our finding of no differences in striatal $\left[{ }^{11} \mathrm{C}\right]$ PHNO binding between abstinent ADP and controls with or without DRD3 blockade initially appears therefore inconsistent. However, recent studies using $\left.{ }^{[1} \mathrm{C}\right]$ PHNO (Boileau et al, 2012; Matuskey et al, 2011; Payer et al, 2013) or $\left[{ }^{11} \mathrm{C}\right] \mathrm{NPA}$ (Narendran et al, 2011) reported no significant differences in striatal binding in stimulant-dependent individuals compared with controls. In one, post-hoc analysis showed that heavy, but not moderate, methamphetamine users had slightly decreased $\left[{ }^{11} \mathrm{C}\right] \mathrm{PHNO}$ binding in dorsal striatum (Boileau et al, 2012). However, in the absence of a DRD2 or DRD3 antagonist, the relative contributions of lower DRD2 or DRD2 ${ }_{\mathrm{HIGH}}$ and higher DRD3 binding could not be determined in these studies.

We were able to combine the DRD3-preferring $\left[{ }^{11} \mathrm{C}\right]$ PHNO with GSK598809, a selective DRD3 antagonist, and did not detect any differences between abstinent ADP and controls in the degree of DRD3 blockade in the striatum or any region. Consistent with previous studies, the largest 
reduction of the $\left[{ }^{11} \mathrm{C}\right] \mathrm{PHNO} V_{\mathrm{T}}$ after DRD3 blockade was detected in the SN-VTA, hypothalamus, and ventral pallidum ( $\sim 40 \%$ ), reflecting levels of DRD3, whereas binding changed very little in the caudate, putamen, and cerebellum (10-14\%) where DRD2 predominate. In the thalamus and VST, the blockade-induced reduction is intermediate $(\sim 20 \%)$ owing to a mixed DRD2/3 signal with $\left[{ }^{11} \mathrm{C}\right]$ PHNO in these regions. The incomplete blockade of $\left[{ }^{11} \mathrm{C}\right] \mathrm{PHNO}$ signal in the DRD3rich regions such as hypothalamus and SN-VTA is due to the moderate dose of GSK598809 used so as not to block DRD2. The 60-mg dose of GSK598809 resulted in equivalent reductions in $\left[{ }^{11} \mathrm{C}\right] \mathrm{PHNO}$ signal to those previously reported (Searle et al, 2013).

Importantly, similarity in the baseline $V_{\mathrm{T}}$ between groups, as seen in striatum, is open to the argument that this could be due to a change in DRD3 and a compensatory change in $\mathrm{DRD} 2_{\mathrm{HIGH}}$. However, in that case the occupancy by GSK598809 would have been greater in the group with the higher DRD3 availability-as at the dose used GSK598809 has negligible binding to $\mathrm{DRD} 2_{\mathrm{HIGH}}$. Therefore, our data strongly suggest that it is unlikely that higher DRD3 levels, alongside lower DRD2 levels, result in similar striatal $\left[{ }^{11} \mathrm{C}\right]$ PHNO binding levels in addiction.

Could a difference in the fraction of DRD2 $2_{\mathrm{HIGH}}$ explain the discrepancy between the newer PET 'agonist studies' $\left(\left[{ }^{11} \mathrm{C}\right] \mathrm{PHNO}\right.$ and $\left.\left[{ }^{11} \mathrm{C}\right] \mathrm{NPA}\right)$ and the previous 'antagonist studies' (eg, mostly $\left[{ }^{11} \mathrm{C}\right]$ raclopride)? Although there is controversy whether $\mathrm{DRD} 2_{\mathrm{HIGH}}$ and $\mathrm{DRD} 2_{\mathrm{LOW}}$ are detectable in vivo (Seeman, 2012; Skinbjerg et al, 2012), a larger fraction of receptors in the high affinity state among ADP compared with controls could in theory explain the lack of difference in binding between these two groups when assessed with an agonist in contrast to the lower total DRD2/3 binding in ADP found with antagonists. Although we cannot rule out this possibility in the current data set, a recent study does not support this. A study using both the antagonist $\left[{ }^{11} \mathrm{C}\right]$ raclopride and the agonist $\left[{ }^{11} \mathrm{C}\right] \mathrm{NPA}$ to measure DRD2 $2_{\mathrm{HIGH}}$ and DRD2 $2_{\mathrm{LOW}}$ reported no differences in DRD2 ${ }_{\mathrm{HIGH}}$ between cocaine addicts and controls (Narendran et al, 2011).

Lastly, a difference in synaptic dopamine levels may contribute to DRD2/3 availability. As a DRD3-preferring DRD2/3 agonist, $\left[{ }^{11} \mathrm{C}\right] \mathrm{PHNO}$ is more sensitive to fluctuations in dopamine levels than an antagonist radioligand (Narendran et al, 2004; Seneca et al, 2006; Shotbolt et al, 2012b). Such differential sensitivity could also contribute to the lack of differences in total $\left[{ }^{11} \mathrm{C}\right]$ PHNO signal but a lower $\left[{ }^{11} \mathrm{C}\right]$ raclopride binding in addicts compared with controls if there are fewer $\mathrm{DRD} 2_{\mathrm{HIGH}}$ combined with less synaptic dopamine in striatum among addicts compared with controls.

Although we found no differences in $\left[{ }^{11} \mathrm{C}\right] \mathrm{PHNO}$ binding in the DRD3-rich region SN-VTA, studies using a reference region approach reported an increase (Boileau et al, 2012; Matuskey et al, 2011). This may be due to us using an arterial input function for full quantification compared with their reference region approach. The latter approach relies on the assumption that the reference region has no specific binding of the PET tracer (Lammertsma and Hume, 1996). However, we found that DRD3 blockade reduces $\left[{ }^{11} \mathrm{C}\right]$ PHNO $V_{\mathrm{T}}$ in the reference region, cerebellum, which suggest the presence of specific binding and therefore contravenes the reference region approach. Consequently,
$\mathrm{BP}_{\mathrm{ND}}$ and $\mathrm{BP}_{\mathrm{P}}$ values should be regarded with caution. We therefore chose $V_{\mathrm{T}}$ as the main outcome measure but reported $\mathrm{BP}_{\mathrm{ND}}$ values for comparison with previous reports using $\left[{ }^{11} \mathrm{C}\right]$ PHNO (Table 2). In addition, due to its close relationship with the pure measure of receptor binding, $\mathrm{BP}_{\mathrm{F}}$, $\mathrm{BP}_{\mathrm{P}}$ is presented. $\mathrm{BP}_{\mathrm{F}}$ is equivalent to the $\mathrm{B}_{\text {avail }} / K_{\mathrm{d}}$ (where $\mathrm{B}_{\text {avail }}=$ the total concentration of available receptors, $K_{\mathrm{d}}=$ $1 /$ the affinity of radioligand to the receptor) and can be calculated by dividing $\mathrm{BP}_{\mathrm{P}}$ by the plasma-free fraction, $f_{\mathrm{P}}$. In the present data set, $f_{\mathrm{P}}$ did not differ between the groups, and thus group differences in $\mathrm{BP}_{\mathrm{P}}$ reflect differences in $\mathrm{B}_{\max } / K_{\mathrm{d}}$. The regional group differences in $\left[{ }^{11} \mathrm{C}\right] \mathrm{PHNO}$ binding as measured by $V_{\mathrm{T}}$ were confirmed when looking at $\mathrm{BP}_{\mathrm{P}}$ data. Importantly, without derivation of $V_{\mathrm{T}}$ in the reference region, cerebellum, the observed significant difference in binding in hypothalamus would have been masked by the slightly higher $\left[{ }^{11} \mathrm{C}\right]$ PHNO $V_{\mathrm{T}}$ in cerebellum among the ADP.

Another important issue is the cold mass of PHNO. To minimize the risk of confound, we kept the injected PHNO mass low, around $1.4 \mu \mathrm{g}$ (as also recommended by Searle et al, 2013). In addition, the aim of the DRD3 blockade in this study was not to evaluate a numerically accurate in vivo affinity for GSK598809 in this population but to block the DRD3 component of the $\left[{ }^{11} \mathrm{C}\right]$ PHNO signal in order to evaluate whether any differences between the healthy volunteers and the alcoholics are due to the DRD2 or the DRD3 component of $\left[{ }^{11} \mathrm{C}\right]$ PHNO. For this purpose, any carry-over of PHNO to the second PET scan added to the GSK598809 would be believed to be negligible as PHNO has a 20-fold selectivity for DRD3 over DRD2, and at the levels of DRD3 occupancy likely induced by PHNO carryover $(<50 \%)$, the effects on DRD2 would be minor $(<5 \%)$.

Our finding of similar striatal $\left[{ }^{11} \mathrm{C}\right] \mathrm{PHNO}$ binding in abstinent ADP and controls could reflect a true lack of difference in dopamine receptor binding between these groups. One important factor that could explain some of the discrepancy between the current and previous studies is the duration of abstinence before entering the study. Like in most of the antagonist studies, the methamphetamine addicts (Boileau et al, 2012) and cocaine addicts using $\left[{ }^{11} \mathrm{C}\right]$ PHNO (Matuskey et al, 2011; Payer et al, 2013), were only about 2 weeks abstinent when scanned. Studies assessing the effect of prolonged alcohol abstinence on the regulation of DRD2/3 binding (Heinz et al, 2004; Hietala et al, 1994; Volkow et al, 1996; Volkow et al, 2002) have generally not detected any signs of recovery. On the other hand, recently (Rominger et al, 2012) striatal DRD2/3 binding has been reported to increase significantly by $29 \%$ between the first day and 1 year of abstinence. Furthermore, it is interesting to note that in a recent $\left[{ }^{11} \mathrm{C}\right]$ raclopride study by Martinez et al (2011), in cocaine addiction the patients who responded to contingency management treatment and thus remained abstinent did not differ from healthy controls in DRD2/3 levels measured pre-treatment. Similar results in methamphetamine-dependent patients have been reported by Wang et al (2012). Therefore, if successful abstinence is associated with striatal DRD2/3 levels similar to healthy controls, this could explain our lack of difference as some of the ADP in our study had been abstinent for more than a year, with the minimum length of abstinence being 39 days. It should be noted that a recent $\left[{ }^{11} \mathrm{C}\right]$ PHNO PET study of cocaine-dependent individuals with a 
7-240-day abstinence range were in line with the results obtained in the studies by Boileau et al (2012) and Matuskey et al (2011), pointing to increased $\left[{ }^{11} \mathrm{C}\right] \mathrm{PHNO}$ binding in substantia nigra (Payer et al, 2013).

Based primarily on preclinical literature, we hypothesized that DRD3 binding would be globally elevated in ADP compared with controls; however higher levels were restricted to the hypothalamus. We believe this to be the first such description in humans as in previous studies by Boileau et al (2012) Matuskey et al (2011) did not report binding in the hypothalamus. The hypothalamus is a relatively small region but the quantification of DRD3 binding here using $\left[{ }^{11} \mathrm{C}\right] \mathrm{PHNO}$ has recently been validated (Tziortzi et al, 2011). Our finding of higher DRD3 binding in the hypothalamus in alcoholism adds to the growing interest in the role of hypothalamus in addiction (AstonJones et al, 2009). Increases in dopamine in the hypothalamus are associated with release of beta-endorphin in nucleus accumbens (Roth-Deri et al, 2003), with DRD2/3 blockade from eticlopride in the hypothalamus reducing beta-endorphin (Doron et al, 2006). Given the high level of DRD3 in the hypothalamus, it is likely that DRD3 contributes to this effect. Therefore, antagonism of the higher hypothalamic DRD3 levels resulting in decreased betaendorphin release in the ventral striatum might underpin how DRD3 antagonists impact on addiction. Consistent with this hypothesis, in vivo human PET imaging data have shown that alcohol consumption induces endogenous opioid release in the ventral striatum (Mitchell et al, 2012).

Concerning the relationship with clinical variables and $\left[{ }^{11} \mathrm{C}\right] \mathrm{PHNO}$ levels, we observed a significant negative relationship between baseline $\left[{ }^{11} \mathrm{C}\right] \mathrm{PHNO}$ and age in some of the brain regions, such as SN-VTA (combined, controls), hypothalamus (ADP), and putamen (combined, ADP). This is in accordance with existing in vitro and in vivo evidence of a significant decline in DRD2/3 density with age (Antonini et al, 1993; Ichise et al, 1998; Ishibashi et al, 2009; Rinne et al, 1990; Severson et al, 1982; Volkow et al, 1998; Wong et al, 1997). In addition, among our ADP, DRD3 blockade in the putamen and thalamus was negatively associated with age. Overall, these results are suggestive of a decline in DRD3 binding with age, in particularly among ADP. No previous $\left[{ }^{11} \mathrm{C}\right] \mathrm{PHNO}$ study has reported a relationship between age and DRD2/3 binding (Boileau et al, 2009; Boileau et al, 2012; Ginovart et al, 2007a; Graff-Guerrero et al, 2009a; Graff-Guerrero et al, 2009b; Shotbolt et al, 2012a; Willeit et al, 2006), which could be due to the narrower age range in their reports and/or to the effect of alcohol.

In conclusion, our study with $\left[{ }^{11} \mathrm{C}\right] \mathrm{PHNO}$ and a DRD3 antagonist, GSK598809, allows for the first time assessment of DRD2 and DRD3 levels in abstinent ADP. Although we did not find decreased striatal DRD2/3 binding in alcoholism as reported using antagonist radiotracers, we were able to show that this was not caused by higher DRD3 levels alongside lower DRD2 as the DRD3 blockade after administration of a selective antagonist was similar between ADP and controls. We did not confirm our hypothesis of a global increase in DRD3 in abstinent alcohol dependence although increased DRD3 binding was detected in the hypothalamus, a region involved in the control of opioid neurotransmission that is a key modulator of the dopaminergic mesolimbic pathway. In the light of evidence for a role of selective DRD3 antagonism in controlling behavior relevant to addiction, this increased DRD3 level in the hypothalamus is likely to be relevant to the therapeutic strategies targeting the DRD3.

\section{FUNDING AND DISCLOSURE}

This work was supported by Medical Research Council grant G0802723, and GlaxoSmithKline supported the PET and MRI brain imaging. Prof. Nutt has served on the advisory boards for Lundbeck, Servier, Pfizer, Reckitt Benkiser, and D\&A Pharma, and has also received honoraria from Bristol Myers Squibb, GlaxoSmithKline (GSK), and Schering-Plough. He has received research funding from P1vital, has share options with P1vital, and receives editorial honoraria from Sage. Prof. LingfordHughes has received honoraria from Janssen-Cilag, Pfizer, Servier, Lundbeck, and from the British Association for Psychopharmacology (BAP). She has provided consultancy to NET Device Corp, and led BAP addiction guidelines, which received funding from Archimedes, Lundbeck, Pfizer, and Schering. Profs Lingford-Hughes and Nutt are both members of the Lundbeck International Neuroscience Foundation and both hold research grants with GSK and Lundbeck. Drs Merlo-Pich, Bani, Beaver, Rabiner, Colasanti, Searle, and Prof Gunn were all GSK employees at the time of the study. Dr Beaver holds shares in GSK, Abbott, and AbbVie and is currently an employee of AbbVie. Dr Rabiner holds GSK shares and has worked as consultant for BioTie, Takeda, and AbbVie. Dr Colasanti is supported by a GSK/ Wellcome Trust training fellowship. Dr Merlo-Pich has been full-time employee of F. Hoffmann-La Roche Ldt since 2012. Dr Waldman has received honoraria from Bayer Healthcare. Prof Gunn is a consultant for GSK, Abbvie, and UCB. Erritzoe, Tziortzi, and Bargiela declared no conflict of interest.

\section{ACKNOWLEDGEMENTS}

We acknowledge all volunteers for their participation as well as the contributions of the staff of the NIHR/Wellcome Trust Imperial CRF and of the GlaxoSmithKline Clinical Imaging Centre at Hammersmith Hospital, London. In addition, we thank Analytical Services International (ASI) at St George's Hospital, University of London, UK, for measurement of GSK598809 in plasma samples.

\section{REFERENCES}

Andreoli M, Tessari M, Pilla M, Valerio E, Hagan JJ, Heidbreder CA (2003). Selective antagonism at dopamine D3 receptors prevents nicotine-triggered relapse to nicotine-seeking behavior. Neuropsychopharmacology 28: 1272-1280.

Antonini A, Leenders KL, Reist H, Thomann R, Beer HF, Locher J (1993). Effect of age on D2 dopamine receptors in normal human brain measured by positron emission tomography and 11Craclopride. Arch Neurol 50: 474-480.

Aston-Jones G, Smith RJ, Moorman DE, Richardson KA (2009). Role of lateral hypothalamic orexin neurons in reward processing and addiction. Neuropharmacology 56: 112-121.

Beck AT (1961). A systematic investigation of depression. Compr Psychiatry 2: 163-170. 
Blair JR, Spreen O (1989). Predicting premorbid IQ: a revision of the national adult reading test. Clin Neuropsychol 3: 129-136.

Bohn MJ, Krahn DD, Staehler BA (1995). Development and initial validation of a measure of drinking urges in abstinent alcoholics. Alcohol Clin Exp Res 19: 600-606.

Boileau I, Guttman M, Rusjan P, Adams JR, Houle S, Tong J et al (2009). Decreased binding of the D3 dopamine receptorpreferring ligand [11C]-(+)-PHNO in drug-naive Parkinson's disease. Brain 132: 1366-1375.

Boileau I, Payer D, Houle S, Behzadi A, Rusjan PM, Tong J et al (2012). Higher binding of the dopamine D3 receptor-preferring ligand $[11 \mathrm{C}]-(+)$-propyl-hexahydro-naphtho-oxazin in methamphetamine polydrug users: a positron emission tomography study. J Neurosci 32: 1353-1359.

Colasanti A, Searle GE, Long CJ, Hill SP, Reiley RR, Quelch D et al (2012). Endogenous opioid release in the human brain reward system induced by acute amphetamine administration. Biol Psychiatry 72: 371-377.

Doron R, Fridman L, Yadid G (2006). Dopamine-2 receptors in the arcuate nucleus modulate cocaine-seeking behavior. Neuroreport 17: $1633-1636$.

George SR, Watanabe M, Seeman P (1985). Dopamine D2 receptors in the anterior pituitary: a single population without reciprocal antagonist/agonist states. J Neurochem 44: 1168-1177.

Ginovart N, Willeit M, Rusjan P, Graff A, Bloomfield PM, Houle S et al (2007a). Positron emission tomography quantification of [11C]-(+)-PHNO binding in the human brain. J Cereb Blood Flow Metab 27: 857-871.

Ginovart N, Willeit M, Rusjan P, Graff A, Bloomfield PM, Houle S et al (2007b). Positron emission tomography quantification of [11C]- $(+)$-PHNO binding in the human brain. J Cereb Blood Flow Metab 27: 857-871.

Graff-Guerrero A, Mamo D, Shammi CM, Mizrahi R, Marcon H, Barsoum P et al (2009a). The effect of antipsychotics on the high-affinity state of D2 and D3 receptors: a positron emission tomography study With [11C]-(+)-PHNO. Arch Gen Psychiatry 66: 606-615.

Graff-Guerrero A, Mizrahi R, Agid O, Marcon H, Barsoum P, Rusjan $\mathrm{P}$ et al (2009b). The dopamine D2 receptors in high-affinity state and D3 receptors in schizophrenia: a clinical [11C]-(+)-PHNO PET study. Neuropsychopharmacology 34: 1078-1086.

Graff-Guerrero A, Redden L, Abi-Saab W, Katz DA, Houle S, Barsoum $P$ et al (2010). Blockade of [11C]( + )-PHNO binding in human subjects by the dopamine $\mathrm{D} 3$ receptor antagonist ABT925. Int J Neuropsychopharmacol 13: 273-287.

Gunn RN, Lammertsma AA, Hume SP, Cunningham VJ (1997). Parametric imaging of ligand-receptor binding in PET using a simplified reference region model. Neuroimage 6: 279-2787.

Halldin C, Farde L, Hogberg T, Mohell N, Hall H, Suhara T et al (1995). Carbon-11-FLB 457: a radioligand for extrastriatal D2 dopamine receptors. J Nucl Med 36: 1275-1281.

Heatherton TF, Kozlowski LT, Frecker RC, Fagerstrom KO (1991). The Fagerstrom Test for Nicotine Dependence: a revision of the Fagerstrom Tolerance Questionnaire. $\mathrm{Br} J$ Addict 86: 1119-1127.

Heidbreder CA, Andreoli M, Marcon C, Hutcheson DM, Gardner EL, Ashby CR Jr. (2007). Evidence for the role of dopamine D3 receptors in oral operant alcohol self-administration and reinstatement of alcohol-seeking behavior in mice. Addict Biol 12: $35-50$.

Heidbreder CA, Gardner EL, Xi ZX, Thanos PK, Mugnaini M, Hagan JJ et al (2005). The role of central dopamine D3 receptors in drug addiction: a review of pharmacological evidence. Brain Res Brain Res Rev 49: 77-105.

Heinz A, Siessmeier T, Wrase J, Hermann D, Klein S, Grusser SM et al (2004). Correlation between dopamine $\mathrm{D}(2)$ receptors in the ventral striatum and central processing of alcohol cues and craving. Am J Psychiatry 161: 1783-1789.
Hietala J, West C, Syvälahti E, Nagren K, Lehikoinene P, Sonninen $\mathrm{P}$ et al (1994). Striatal D2 dopamine receptor binding charactereristics in vivo in patients with alcohol dependence. Psychopharmacology 116: 285-290.

Ichise M, Ballinger JR, Tanaka F, Moscovitch M St, George-Hyslop PH, Raphael D et al (1998). Age-related changes in D2 receptor binding with iodine-123-iodobenzofuran SPECT. J Nucl Med 39: 1511-1518.

Ishibashi K, Ishii K, Oda K, Kawasaki K, Mizusawa H, Ishiwata K (2009). Regional analysis of age-related decline in dopamine transporters and dopamine D2-like receptors in human striatum. Synapse 63: 282-290.

Lammertsma AA, Hume SP (1996). Simplified reference tissue model for PET receptor studies. Neuroimage 4: 153-158.

Landwehrmeyer B, Mengod G, Palacios JM (1993). Dopamine D3 receptor mRNA and binding sites in human brain. Brain Res Mol Brain Res 18: 187-192.

Leff P (1995). The two-state model of receptor activation. Trends Pharmacol Sci 16: 89-97.

Lingford-Hughes AR, Welch S, Peters L, Nutt DJ (2012). BAP updated guidelines: evidence-based guidelines for the pharmacological management of substance abuse, harmful use, addiction and comorbidity: recommendations from BAP J Psychopharmacol 26: 899-952.

Liu IS, George SR, Seeman P (2000). The human dopamine D2(Longer) receptor has a high-affinity state and inhibits adenylyl cyclase. Brain Res Mol Brain Res 77: 281-284.

Martinez D, Carpenter KM, Liu F, Slifstein M, Broft A, Friedman AC et al (2011). Imaging dopamine transmission in cocaine dependence: link between neurochemistry and response to treatment. Am J Psychiatry 168: 634-641.

Martinez D, Kim JH, Krystal J, Abi-Dargham A (2007). Imaging the neurochemistry of alcohol and substance abuse. Neuroimaging Clin N Am 17: 539-555.

Matuskey D, Gallezot J-D, Lim K, Zheng M, Lin S, Carson R et al (2011). Subcortical D3/D2 receptor binding in cocaine dependent humans. J Nucl Med 52: 1284.

Mitchell JM, O'Neil JP, Janabi M, Marks SM, Jagust WJ, Fields HL (2012). Alcohol consumption induces endogenous opioid release in the human orbitofrontal cortex and nucleus accumbens. Sci Transl Med 4: 116ra116.

Mugnaini M, Iavarone L, Cavallini P, Griffante C, Oliosi B, Savoia C et al (2013). Occupancy of brain dopamine D3 receptors and drug craving: a translational approach. Neuropsychopharmacology 38: 302-312.

Mukherjee J, Yang ZY, Brown T, Lew R, Wernick M, Ouyang X et al (1999). Preliminary assessment of extrastriatal dopamine D-2 receptor binding in the rodent and nonhuman primate brains using the high affinity radioligand, 18F-fallypride. $\mathrm{Nucl}$ Med Biol 26: 519-527.

Murray AM, Ryoo HL, Gurevich E, Joyce JN (1994). Localization of dopamine D3 receptors to mesolimbic and D2 receptors to mesostriatal regions of human forebrain. Proc Natl Acad Sci USA 91: 11271-11275.

Narendran R, Hwang DR, Slifstein M, Talbot PS, Erritzoe D, Huang $\mathrm{Y}$ et al (2004). In vivo vulnerability to competition by endogenous dopamine: comparison of the D2 receptor agonist radiotracer $(-)-\mathrm{N}-[11 \mathrm{C}]$ propyl-norapomorphine ([11C]NPA) with the D2 receptor antagonist radiotracer [11C]-raclopride. Synapse 52: 188-208.

Narendran R, Martinez D, Mason NS, Lopresti BJ, Himes ML, Chen $\mathrm{CM}$ et al (2011). Imaging of dopamine D2/3 agonist binding in cocaine dependence: a [11C]NPA positron emission tomography study. Synapse 65: 1344-1349.

Narendran R, Slifstein M, Guillin O, Hwang Y, Hwang DR, Scher E et al (2006). Dopamine (D2/3) receptor agonist positron emission tomography radiotracer $[11 \mathrm{C}]-(+)-\mathrm{PHNO}$ is a D3 receptor preferring agonist in vivo. Synapse 60: 485-495. 
Payer DE, Behzadi A, Kish SJ, Houle S, Wilson AA, Rusjan PM et al (2013). Heightened D dopamine receptor levels in cocaine dependence and contributions to the addiction behavioral phenotype: a positron emission tomography study with [C](+)-PHNO. Neuropsychopharmacology 39: 321-328.

Plisson C, Huiban M, Pampols-Maso S, Singleton G, Hill SP, Passchier J (2012). Automated preparation of the dopamine D2/3 receptor agonist ligand [11C]-(+)-PHNO for human PET imaging studies. Appl Radiat Isot 70: 380-387.

Rabiner EA, Slifstein M, Nobrega J, Plisson C, Huiban M, Raymond $\mathrm{R}$ et al (2009). In vivo quantification of regional dopamine-D3 receptor binding potential of $(+)$-PHNO: Studies in non-human primates and transgenic mice. Synapse 63: 782-793.

Rehm J, Mathers C, Popova S, Thavorncharoensap M, Teerawattananon Y, Patra J (2009). Global burden of disease and injury and economic cost attributable to alcohol use and alcohol-use disorders. Lancet 373: 2223-2233.

Rinne JO, Lonnberg P, Marjamaki P (1990). Age-dependent decline in human brain dopamine D1 and D2 receptors. Brain Res 508: 349-352.

Rominger A, Cumming P, Xiong G, Koller G, Boning G, Wulff M et al (2012). [18F]Fallypride PET measurement of striatal and extrastriatal dopamine D 2/3 receptor availability in recently abstinent alcoholics. Addict Biol 17: 490-503.

Roth-Deri I, Zangen A, Aleli M, Goelman RG, Pelled G, Nakash R et al (2003). Effect of experimenter-delivered and self-administered cocaine on extracellular beta-endorphin levels in the nucleus accumbens. J Neurochem 84: 930-938.

Searle G, Beaver JD, Comley RA, Bani M, Tziortzi A, Slifstein M et al (2010). Imaging dopamine D3 receptors in the human brain with positron emission tomography, [11C]PHNO, and a selective D3 receptor antagonist. Biol Psychiatry 68: 392-399.

Searle GE, Beaver JD, Tziortzi A, Comley RA, Bani M, Ghibellini G et al (2013). Mathematical modelling of [(11)C]-(+)-PHNO human competition studies. Neuroimage 68: 119-132.

Seeman P (2012). Dopamine agonist radioligand binds to both D2High and D2Low receptors, explaining why alterations in D2High are not detected in human brain scans. Synapse 66: 88-93.

Seneca N, Finnema SJ, Farde L, Gulyas B, Wikstrom HV, Halldin C et al (2006). Effect of amphetamine on dopamine D2 receptor binding in nonhuman primate brain: a comparison of the agonist radioligand [11C]MNPA and antagonist [11C]raclopride. Synapse 59: 260-269.

Severson JA, Marcusson J, Winblad B, Finch CE (1982). Agecorrelated loss of dopaminergic binding sites in human basal ganglia. J Neurochem 39: 1623-1631.

Shotbolt P, Tziortzi AC, Searle GE, Colasanti A, van der Aart J, Abanades $S$ et al (2012a). Within-subject comparison of [(11)C]$(+)$-PHNO and [(11)C]raclopride sensitivity to acute amphetamine challenge in healthy humans. J Cereb Blood Flow Metab 32: 127-136.

Shotbolt P, Tziortzi AC, Searle GE, Colasanti A, van der Aart J, Abanades $S$ et al (2012b). Within-subject comparison of [(11)C]$(+)$-PHNO and [(11)C]raclopride sensitivity to acute amphetamine challenge in healthy humans. J Cereb Blood Flow Metab 32: 127-136.

Skinbjerg M, Sibley DR, Javitch JA, Abi-Dargham A (2012). Imaging the high-affinity state of the dopamine D2 receptor in vivo: fact or fiction? Biochem Pharmacol 83: 193-198.

Skinner HA, Sheu WJ (1982). Reliability of alcohol use indices. The lifetime drinking history and the MAST. J Stud Alcohol 43: $1157-1170$
Sokoloff P, Giros B, Martres MP, Bouthenet ML, Schwartz JC (1990). Molecular cloning and characterization of a novel dopamine receptor (D3) as a target for neuroleptics. Nature 347: 146-151.

Spielberger CD, Gorsuch RL, Lushene R, Vagg PR, Jacobs GA (1983). Manual for the State-Trait Anxiety Inventory (Form Y). Consulting Psychologists Press: Palo Alto, CA, USA.

Stockwell T, Sitharthan T, McGrath D, Lang E (1994). The measurement of alcohol dependence and impaired control in community samples. Addiction 89: 167-174.

Strange PG (2001). Antipsychotic drugs: importance of dopamine receptors for mechanisms of therapeutic actions and side effects. Pharmacol Rev 53: 119-133.

Suzuki M, Hurd YL, Sokoloff P, Schwartz JC, Sedvall G (1998). D3 dopamine receptor mRNA is widely expressed in the human brain. Brain Res 779: 58-74.

Tanner M, Gambarota G, Kober T, Krueger G, Erritzoe D, Marques JP et al (2012). Fluid and white matter suppression with the MP2RAGE sequence. J Magn Reson Imaging 35: 1063-1070.

Thanos PK, Katana JM, Ashby CR Jr., Michaelides M, Gardner EL, Heidbreder CA et al (2005). The selective dopamine D3 receptor antagonist SB-277011-A attenuates ethanol consumption in ethanol preferring (P) and non-preferring (NP) rats. Pharmacol Biochem Behav 81: 190-197.

Tziortzi AC, Searle GE, Tzimopoulou S, Salinas C, Beaver JD, Jenkinson $M$ et al (2011). Imaging dopamine receptors in humans with [11C]-(+)-PHNO: dissection of D3 signal and anatomy. Neuroimage 54: 264-277.

Vengeliene V, Leonardi-Essmann F, Perreau-Lenz S, GebickeHaerter P, Drescher K, Gross G et al (2006). The dopamine D3 receptor plays an essential role in alcohol-seeking and relapse. FASEB J 20(13): 2223-2233.

Videbaek C, Toska K, Scheideler MA, Paulson OB, Moos Knudsen G (2000). SPECT tracer [(123)I]IBZM has similar affinity to dopamine D2 and D3 receptors. Synapse 38: 338-342.

Volkow ND, Wang GJ, Fowler JS, Ding YS, Gur RC, Gatley J et al (1998). Parallel loss of presynaptic and postsynaptic dopamine markers in normal aging. Ann Neurol 44: 143-147.

Volkow ND, Wang GJ, Fowler JS, Logan J, Hitzemann R, Ding YS et al (1996). Decreases in dopamine receptors but not in dopamine transporters in alcoholics. Alcohol Clin Exp Res 20: 1594-1598.

Volkow ND, Wang GJ, Fowler JS, Tomasi D (2012). Addiction circuitry in the human brain. Annu Rev Pharmacol Toxicol 52: 321-336.

Volkow ND, Wang GJ, Maynard L, Fowler JS, Jayne B, Telang F et al (2002). Effects of alcohol detoxification on dopamine D2 receptors in alcoholics: a preliminary study. Psychiatry Res 116: 163-172.

Wang GJ, Smith L, Volkow ND, Telang F, Logan J, Tomasi D et al (2012). Decreased dopamine activity predicts relapse in methamphetamine abusers. Mol Psychiatry 17: 918-925.

Willeit M, Ginovart N, Kapur S, Houle S, Hussey D, Seeman P et al (2006). High-affinity states of human brain dopamine D2/3 receptors imaged by the agonist [11C]- $(+)-$ PHNO. Biol Psychiatry 59: 389-394.

Wong DF, Young D, Wilson PD, Meltzer CC, Gjedde A (1997). Quantification of neuroreceptors in the living human brain: III. D2-like dopamine receptors: theory, validation, and changes during normal aging. J Cereb Blood Flow Metab 17: 316-330. 